\title{
Correlates of Reproductive Success In a Caribbean Village
}

\author{
Mark V. Flinn ${ }^{1}$
}

Genealogical, demographic, and economic data collected in a rural Trinidadian village indicate that: (1) individuals with more land have more offspring, (2) males with more land have higher mating success, (3) young adults with parents resident in the village have higher reproductive success, and (4) the residence of father has a strong effect on young adult male reproductive success, but apparently has no effect on young adult female reproductive success, suggesting a gender bias in nepotism. The results indicate that there are important gender differences in the effect of resources on reproduction and in patterns of parent-offspring interaction.

KEY WORDS: reproductive success; resources; gender differences; nepotism; Trinidad.

The birds who does have the feed will hum; those that isn' got the feed wouldn' be able to hum.

Coconut villager, 1956 (from Rodman, 1971, p. xii)

\section{INTRODUCTION}

Differential fitness is the keystone of evolutionary theory. Studies of human populations, however, are often limited by a lack of data on the reproductive success of individuals. In this paper, demographic and economic data collected during fieldwork in a rural Trinidadian village are analyzed. The purpose of the analysis is to test alternative hypotheses from an-

\footnotetext{
'Department of Anthropology, Michigan Society of Fellows, and Division of Biological Sciences, University of Michigan, Ann Arbor, Michigan 48109.
} 
thropological, biological, and economic theories concerning the relationship between socio-economic success and reproductive success.

Since Williams (1966), most biologists have accepted the validity of the general hypothesis that organisms evolve to amass resources in ways that maximize the reproduction of their genetic materials (via mating and assistance to genetic relatives). For example, Alexander $(1979$, p. 17) notes that natural selection favors organisms that "use the least energy and take the lowest risks in securing the highest quality and quantity of resources and converting them into their own genetic materials."

Many students of human behavior have suggested that human strivings toward economic and social success might be related to an evolutionary history of economically and socially successful individuals outreproducing less successful individuals (Alexander, 1974; Bates and Lees, 1979; Betzig, 1983; Chagnon, 1979; Chance, 1962; Daly and Wilson, 1983; Fisher, 1958; Fox, 1972; Hill, 1984; Hirschleifer, 1978; Irons, 1979, 1983; Neel, 1980; Vayda and McCay, 1975; Vining, in press; Wilson, 1975, 1978). As Chance (1962, p. 128) puts it, "the ascent of [hu]man[s] has been due in part to a competition for social position, giving access to the trigonal sphere of social activity in which success was rewarded by a breeding premium..." At issue here is whether or not the "economic human" is a product of evolution. A related problem is whether or not economic strategies maximize fitness in contemporary environments.

Previous studies of the relationship between resources and fitness usually have been based on census data that document female reproductive success. Several recent ethnographic studies, however, suggest that there are important differences between the reproductive strategies of males and females (Chagnon, 1979; Chagnon, Flinn, and Melancon, 1979; Kaplan and Hill, 1985; Irons, 1979; Turke and Betzig, in press). Moreover, gender differences in the relationship between resource control and reproductive success are a critical aspect of current mating systems theory (Trivers, 1972; Emlen and Oring, 1977; Borgia, 1979; Thornhill and Alcock, 1983; Vehrencamp and Bradbury, 1984). Here, alternative hypotheses from anthropological and biological theories are tested by examining the associations between: (1) resources (land ownership) and male and female reproductive success, (2) resources (land ownership) and male and female "mating success," and (3) assistance from kin (residence of parents in village) and young adult male and young adult female reproductive success. The results suggest a complex relationship between resources, nepotism, and fitness. Before presenting these results, I will first briefly describe the study site and field techniques so as to provide a basis for understanding the data base. 


\section{DESCRIPTION OF THE FIELD SITE}

The village of "Grande Anse" is located on the northern coast of Trinidad. It is isolated from the more heavily populated and economically developed central and western areas of the country by the steep and densely vegetated slopes of the Northern Range, which rise directly from the Caribbean sea. Most of the 342 inhabitants live in the small pocket of relatively level alluvial deposits from the Grande Anse river. The surrounding hillsides are cultivated with cocoa, coffee, banana, and citrus as cash crops, and cassava, corn, dasheen, and vine tubers as subsistence items. Further from the village, the topography is too severe for cultivation. Most of this land is undeveloped government forest reserve.

There are a variety of ways to make a living in Grande Anse. Some people are more prosperous than others. Most villagers have several parttime occupations, such as cocoa cultivation, fishing, and carpentry, or road work (government job), shopkeeping, and gardening. A majority of villagers have rights to cultivable land and expend some effort growing both cash crops, e.g., cocoa, and bananas, and subsistence crops. But the profits are slim and the work hard, so cultivation is the primary occupation of very few villagers today (about $13 \%$ of adult males, $8 \%$ of adult females). In the past (prior to the post-World War II government job programs), however, cultivation was the major occupation of most village residents.

In summary, there is nothing particularly unusual about Grande Anse. It has many of the social and economic characteristics described by ethnographers of other rural villages in the Caribbean area (Smith, 1962; Rodman, 1971). The "emic" goals of most villagers include achieving moderate economic prosperity, being well liked by their fellow villagers, and having children. As in many other societies, however, there is variability in the attainment of these goals. Because anthropologists have traditionally focused upon the social "system" as a whole, the analysis of individual variability has received less attention (Barth, 1967; Pelto and Pelto, 1975).

\section{METHODS AND FIELD TECHNIQUES}

During July and August, 1978, and October, 1979 through April, 1980, field research was conducted in the village of "Grande Anse" and surrounding areas. The methodology and field techniques utilized in this study were designed to gather and analyze data that most reliably and objectively described: (1) genealogical relatedness, (2) economic assets and occupations, (3) past and cur- 
rent mating and marriage relationships, (4) residence, (5) day-to-day behavior ("instantaneous scan sample"), (6) the productivity of certain horticultural and subsistence activities, and \& (7) the flow of material resources among individuals, i.e., gifts and inheritances. This paper is primarily concerned with analysis of the first three types of information, hence, description of mehtods will be limited to them (for a more complete discussion see Flinn, 1983).

Collecting accurate genealogies was a primary objective of the field study. Initially informants were interviewed from each household, usually adult females, obtaining the names, genealogical relationships, ages, and current residences of all the relatives (blood and affinal) that they could remember. These interviews were well received, as most villagers were pleased that someone was interested in their ancestry. Upon returning from the interview, I assigned unique I.D. numbers to each individual collected in the genealogies and put all of the above information on $3 \times 5$ index cards for each individual. This information was later analyzed by computer.

Because most villagers were related to many other villagers (Flinn, 1983), these genealogies overlapped extensively. In the areas of overlap, discrepancies were occasionally encountered. I usually asked "Tantie," a 52-year-old woman in whose house I resided, about such discrepancies. Most of them involved a question of paternity; informants had given me different males as the father of an individual. The usual tendency was for a woman to initially acknowledge fewer fathers for her offspring (or for her close relatives' offspring), than did her more distant relatives that were interviewed. Tantie has lived in Grande Anse all her life and is related to a majority of her fellow villagers. She is extremely knowledgeable about the village, and could usually suggest whom I should question about the discrepancy. As I became more familiar with the village, I could decide myself who to question, but at first I was hesitant for fear of insulting someone. I learned to emphasize that it was important for me to know precise blood, i.e., genetic, relatedness, and to convey indirectly that $I$ had no moral qualms in regard to illegitimacy; this resulted in genealogies with fewer discrepancies in the first interview.

To the best of my knowledge the genealogies collected are correct as understood by the villagers; there may be a few errors that they were unaware of or that they were able to deceive me about. In four cases, some villagers held differing opinions; these involved situations of potential cuckoldry unknown to males who assumed they were the fathers. For obvious reasons, I did not challenge the supposed father's account. However, in three of the four cases, I was convinced by accounts from other informants that cuckoldry had occurred, and put the supposed cuckolder down as the genetic father in the genealogies. I would estimate that the genealogies are about $95 \%$ ac- 
curate. Lacking paternity exclusion tests from blood samples, I cannot verify this. I note, however, that paternity recognition is of considerable concern to the villagers, who seem very adept at it, particularly the older females (see also Daly and Wilson, 1982). Kin recognition is a topic that I hope to investigate more thoroughly in the near future.

Another objective of the study was to gather accurate mating histories. Collection of mating histories occurred over the entire period of the field study, and overlapped with the collection of accurate genealogies. For both sets of data it is useful to seek redundant information from several informants, to allow for cross-checking (Chagnon, 1974). Another source of information was the registry of births. This was not very reliable because it systematically avoided illegitimacy by ascribing paternity to a woman's legal husband. It was useful for acquiring birthdates. Information about recent and current mating relationships was much more reliable and complete, partly because informants' memories were fresher, and partly because they were observable at the time of study. In this paper, only data from genealogies are utilized to compute variables such as reproductive success and mating success, because the genealogical information is much more complete and reliable than mating histories.

Data were collected on economic assets and occupations by interview (What land do you own, rent, cultivate? What major possessions do you "own," e.g., house, mule, radio? What "jobs" do you have, and how much income do you make?). This survey was conducted directly with informants at their place of residence, and in some cases, was corroborated by interviews with other villagers. Government land ownership maps were useful for corroborating information about land ownership (especially the size of landholdings) and for establishing patterns of "legal" inheritance.

There were two individuals in the village from whom reliable information could not be obtained. One individual was imprisoned shortly after I arrived. Another was initially concerned that I might be a spy, so I did not actively pursue information about him.

Many aspects of the interpersonal relationships that I developed with the villagers are undoubtedly reflected in the quality of the data. The reliability and thoroughness of the genealogies, mating histories, and economic data were unavoidably affected by the extent to which I had developed friendships and other ties. The data are most extensive for those individuals with whom I was most familiar, such as the members and close kin of the household in which I resided. Nonetheless, it is unlikely that such biases would introduce any systematic trends that might affect tests of the sorts of hypotheses proposed here. The data analyzed in this paper, moreover, were complete for each villager (aside from the two individuals noted above). 


\section{RESOURCES AND REPRODUCTION IN GRANDE ANSE}

Let us consider first the hypothesis that individuals with more resources have higher reproductive success. During my fieldwork, I gathered information about three types of resources that individuals control: land "ownership," income, and material possessions, e.g., donkeys, houses, and radios. These three types of resources are correlated positively; individuals with more land tend to have higher incomes and to have more material possessions, although a few individuals had high incomes but no land. Land and income are associated with different patterns of mating relationships (Flinn, 1983; Clarke, 1957), perhaps because of the concern about land inheritance. In this paper, data shall be presented only on land ownership, because it is the most stable resource over time, and because it was easiest to measure accurately. Because land is worked jointly by household family members and because the benefits are distributed among household family members, household land ownership was used as the measurement of individual land ownership (no correction for the number of household members was made).

Figure 1 presents data on land ownership and reproductive success (offspring surviving past 1 month) among adult villagers (males over 20 and females over 18). There is a positive association; individuals from households with more land tend to have more children (one-tailed $t$-tests, $p<.05$, except for the difference between the means of the 6-10 acre and $>10$ acre categories). At this point, therefore, we cannot reject the hypothesis that in this population, resource control increases fitness. Evidence for a positive relationship between socio-economic status and reproductive success sometimes has been readily accepted as proof of a sociobiological hypothesis. There appears, however, to be considerable cross-cultural variability in this relationship (Vining, in press; Flinn and Low, 1986). Consequently it is important to examine the other factors that might be associated with wealth and reproduction.

There are several possible reasons for the positive association between resource control and reproductive success.

First, improved material conditions might increase offspring survival (Driver, 1963). Unfortunately, the sample size is insufficient to test for offspring mortality differences; however, the overall mortality rates were not high enough to account for the association. The genealogies indicate that the infant (ages 0-1) mortality rate in the village for the period 1940-1980 was about $4 \%$, although this figure is not very reliable and may be low due to underreporting. The current figures for Trinidad, however, also are quite low, about 3\% (Central Statistical Office, Government of Trinidad and Tobago). Although decreased offspring mortality may contribute to higher fitness for landed individuals, the low rate of mortality indicates that there must be other, more important factors. 


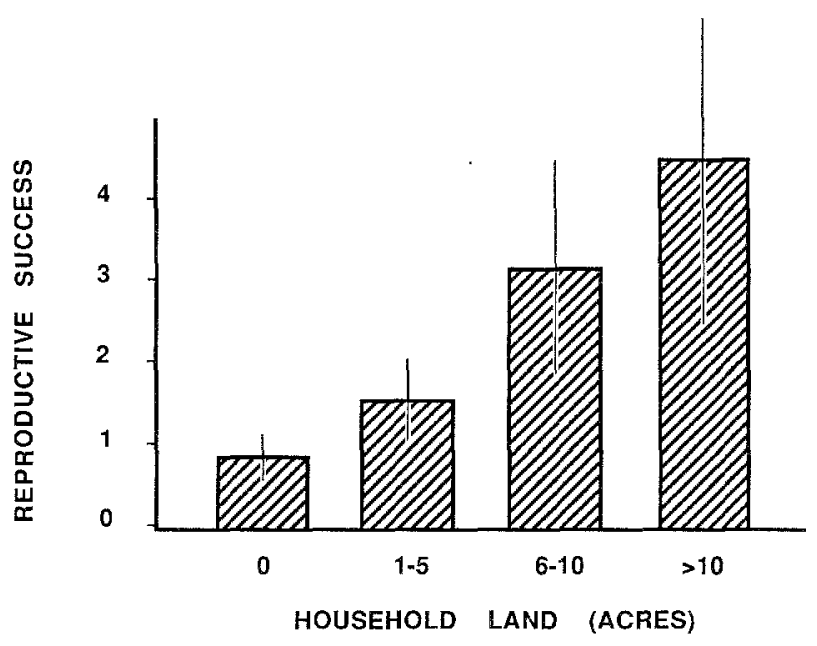

Fig. 1. Land and reproductive success. Adult individuals (males over 20 years of age, females over 18 years of age) from household with more land have higher reproductive success (offspring surviving to 1 year of age). Confidence intervals of $95 \%$ for the mean of each category are indicated by the vertical lines. Sample sizes for the four categories are: $48,44,36$, and 26 . Significance levels of $t$-tests for differences between the means are: 0 vs. $1-5 ; p=.014 ; 1-5$ vs. $6-10, p=.017 ; 6-10$ vs. $>10, p=.6$ (not significant).

Second, the land-fitness association might be due to improved nutrition in landed families. I collected some data on diets, but do not have intake records or anthropometric measurements sufficient to test this hypothesis. However, if better nutrition is the major factor causing landed individuals to have more offspring, then there should be a gender bias in the correlation. If we assume that nutrition affects female reproductive success more than male reproductive success, then we can predict that females from landed households have more offspring. This prediction is tested below.

Third, the association might be a spurious result of a correlation between age and land ownership; the data indicate, however, only a very slight correlation ( $r=.06$, not significant), so it is unlikely that age is the major factor accounting for the association between land and fitness. In other populations, there often is a positive correlation between age and land ownership, as individuals acquire land over time. In Grande Anse, however, most individuals currently acquire land by inheritance. Land tenure is a complicated affair with no clear-cut inheritance rules. In general, all surviving children, and sometimes additional relatives, legally inherit the land, but local kin usually gain all de facto rights (see Besson, 1979). Young men are almost equally 
as likely as older males to have land via inheritances, or to be members of households that have land. There also were a number of older males ( $>60$ years) resident in the village that were landless laborers in earlier days during the cocoa boom. These older, landless males tended to balance out the age/land distribution. Because the relationship between age and land ownership is quite complex, I have not yet determined a proper means of controlling for age (preliminary examination of land and fitness by age cohort indicates that the association between land and fitness is stronger for older males, whereas an association between income and fitness is stronger for younger males, suggesting a change in the relative importance of these two resources for mating success). The analyses presented in this paper are uncorrected for age; however, I do not believe this shortcoming biases the results in favor of any of the hypotheses tested here.

Fourth, reproduction might be a response to a perceived need for labor (Becker, 1981; Goody, 1976; Meillasoux, 1972). This hypothesis seems unlikely because the plots of land owned and worked by villagers are rather small and are evidently capable of being efficiently cultivated by one or two workers. Moreover, at least some reproduction may involve "illegitimate" offspring who are unlikely to inherit or work the land. Nonetheless, villagers do express concern about having offspring, especially sons, to help them cultivate. A logical prediction from the "labor needs" hypothesis is that there should be no difference by gender in the association between land ownership and reproductive success, because increased reproduction of landed individuals would result from the increased number of legitimate heirs and workers produced by the "wife" in the household (hence husbands and wives would have equal reproductive success).

Fifth, resource control might be associated with mate acquisition (Borgia, 1979; Emlen and Oring, 1977; Flinn and Low, 1986; Orians, 1969; Vehrencamp and Bradbury, 1984). If this is the case, then male reproductive success should be more highly associated with land ownership, because male reproductive success is more likely to increase with additional mates than is female reproductive success (Bateman, 1948; Trivers 1972). This prediction is contra that from the "nutrition" and the "labor needs" hypotheses (stated previously), which predict that male reproductive success will not show a stronger association with land ownership than will female reproductive success.

Figure 2 shows the association between land ownership and reproductive success for the two sexes. Male reproductive success is more strongly associated with land ownership than is female reproductive success (for males, $p<.05$ for one-tailed $t$-tests except for the difference between the 6-10 and $>10$ acre categories; for females, only the difference between the 0 and $>$ 10 acre categories is significant at the $p<.05$ level). These results are sup- 
portive of the "mate acquisition" hypothesis. However, we still do not know how prosperous males are achieving higher reproductive success.

\section{RESOURCE CONTROL AND MATING SUCCESS}

Let us now consider the hypothesis that male reproductive success is more strongly associated with land ownership than is female reproductive success because landed males have offspring with additional mates. Figure 3 shows the relationship between the number of mates with whom an individual has had offspring (this is not equivalent to the number of mates an individual has had; only those mates that produced offspring are con-

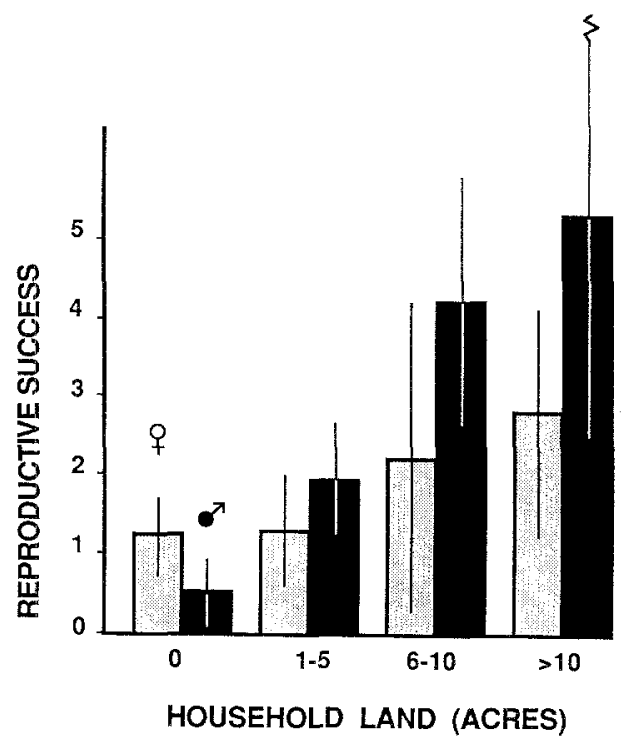

Fig. 2. Land and reproductive success of females and males. The association between land and reproductive success is much stronger for adult males (black bars) than for adult females (gray bars). Confidence intervals of $95 \%$ for the mean of each category are indicated by the vertical lines. Sample sizes for the eight categories are: $22,26,23,21,19,17,13$, and 13. Significance levels of $t$-tests for differences between the means for females are: 0 vs. $1-5, p=.8$ (n.s.); $1-5$ vs. $6-10, p=.5$ (n.s.); $6-10$ vs. $>10, p=.6$ (n.s.). And for males: 0 vs. $1-5, p=.001: 1-5$ vs. $6-10$, $p=.009 ; 6-10$ vs. $>10, p=.7$ (n.s.). 
sidered here because that is a far more reliable datum) and household land ownership. Clearly males with land have offspring by more mates than less prosperous males (one-tailed $t$-tests, $p<.05$ for differences among all categories except between 6-10 and $>10$ ). On the other hand, although females in households with land have slightly more offspring (Fig. 2), they evidently do not have them by more mates.

Here the question emerges, how is it that resources lead to higher mating success, i.e., what are the day-to-day consequences of land ownership that result in landed males having offspring via more mates? I can only offer observations of a qualitative nature. There seemed to be several factors involved, and these varied among individual cases. Female villagers generally expressed a preference for wealthier mates, and associated factors such as being well-dressed. Females were more receptive to males that brought "presents" to them; in general, mating relationships entailed gift-giving by males. The "affordability" of offspring also might affect reproductive activities, although conscious family planning involving the use of modern contraceptives was

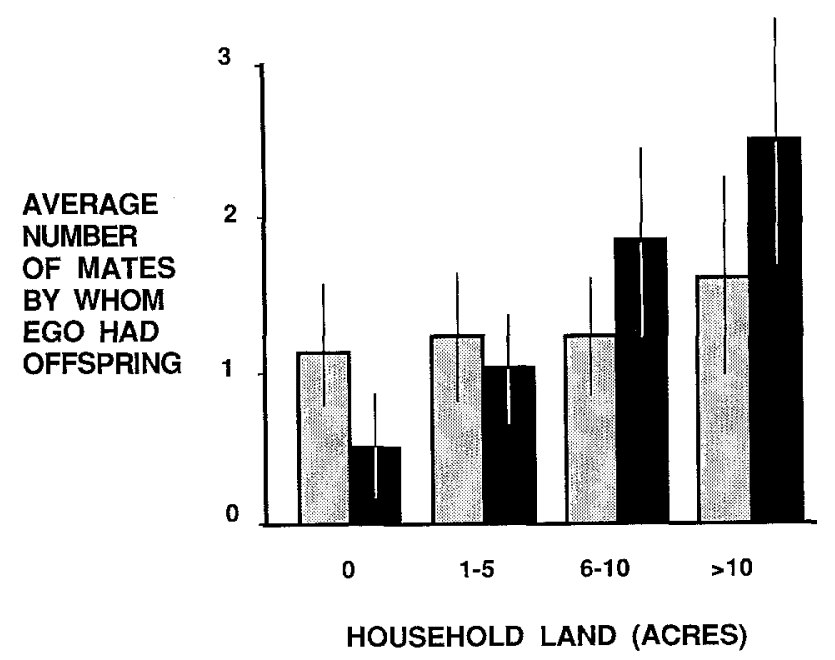

Fig. 3. Land ownership and mating success. The association between land and mating success (number of mates by whom an individual has had offspring) is much stronger for males (black bars) than for females (gray bars). Confidence intervals of $95 \%$ for the mean of each category are indicated by the vertical lines. Sample sizes for the eight categories are: $22,26,23,21,19$, 17,13 , and 13. Significance levels of $t$-tests for differences between the means for females are: 0 vs. $1-5, p=.8$ (n.s.); $1-5$ vs. $6-10$, $p=.9$ (n.s.); $6-10$ vs. $>10, p=.6$ (n.s.); and 0 vs. $>10, p$ $=.2$ (n.s.). And for males: 0 vs. $1-5, p=.024 ; 1-5$ vs. $6-10, p$ $=.035 ; 6-10$ vs. $>10, p=.20$ (n.s.); and 0 vs. $6-10, p=.006$; $1-5$ vs. $>10, p=.002$. 
uncommon (and limited to the wealthier households, which might explain the absence of significant differences between the 6-10 and $>10$ categories). An additional factor could be that the more prosperous villagers had better diets; in general, they appeared to be larger, healthier, and better nourished (this seemed true of the young males that I played basketball with, but I do not have the anthropometric data necessary to test this hypothesis). But again, it is not clear why this should result in a stronger association between land and male reproductive success except, perhaps, as a consequence of female choice (for "healthier" males).

It is also possible that females were strategically claiming landed males as the fathers of their offspring in order to obtain more resources for themselves and/or for their offspring. However, it is unlikely that females were able to systematically deceive males (and their kin) in this regard, although some individuals expressed concern about the possibility of being deceived. Moreover, illegitimate offspring usually received less care and material goods; hence, the best strategy for obtaining male parental care apparently was to claim that the "husband" was the father, even if the "husband" was a poor male. There were several cases where offspring received less paternal assistance because their mothers acknowledged (perhaps unwillingly, because the "evidence," usually physical resemblance, was fairly obvious to others, so denial was unlikely to be successful) that a male other than her husband was the genetic father of the child (Flinn, in press a). Again, the results rely upon accurate genealogies, which although they are correct to the best of my knowledge, can only be positively confirmed by paternity exclusion blood tests.

The most important effect of resource control on mate competition appeared to involve what might loosely be termed the "politics" of arranging mating relationships. The older members of the village exerted considerable influence upon mating relationships. Young males with influential parents tended to be more successful courters, probably in large part due to approval by the young females' parents and other kin. Young males from households with land apparently had an advantage in mate competition because material resources are evidently associated with "social resources." To test this hypothesis, I shall now examine the association between kinship and reproductive success.

\section{KINSHIP AND REPRODUCTION}

Inclusive fitness theory (Hamilton, 1964; West-Eberhard, 1975) predicts that individuals should help their relatives in appropriate circumstances. Such help should ultimately result in higher fitness for the recipient. The best test 
of the hypothesis that help from kin increases reproductive success that I can determine from my data is to analyze reproductive success and parental residence. The prediction is that young adults with parents resident in the village will have higher reproductive success than young adults without parents resident in the village. Figure 4 supports this hypothesis; clearly, young adults (males aged 20-30, females aged 18-28) with parents resident in the village have more offspring (one-tailed $t$-tests, $p<.1$ for a difference between each category).

Because behavioral scan data indicate that parent-offspring interactions are gender-biased (Flinn, 1983, in press), i.e., fathers interact more with sons, and mothers interact more with daughters, we may further predict that a gender bias exists in the residence/reproduction association. Male reproductive success should be more dependent upon residence of father, and female reproductive success should be more dependent upon the residence of mother.

Figure 5 shows the reproductive success of young adult males (aged 20-30) and females (aged 18-28) according to parental residence. The data indicate that parental residence has a strong gender-biased association with reproductive success. For males, residence of father is particularly impor-

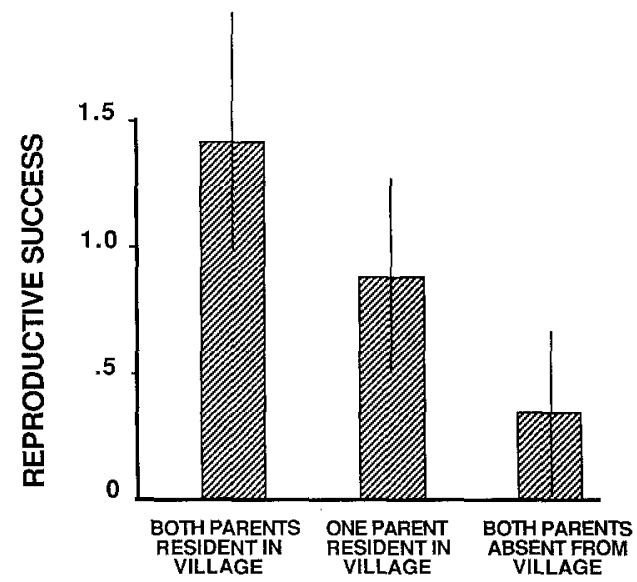

Fig. 4. Parental residence and reproductive success of young adults. Young adults (males aged 20-30, females aged 18-28) with parents resident in the village tend to have higher reproductive success than young adults without parents resident in the village (due to emigration or death). Confidence intervals of $95 \%$ for the mean of each category are indicated by the vertical lines. Sample sizes for the three categories are: 26,27 , and 10 . Significance levels of $t$-tests for differences between the means are: both parents vs. one parent, $p=.073$; one parent vs. no parents, $p=.085$; both parents vs, no parents, $p$ $=.005$. 
tant. Males with resident fathers averaged much higher reproductive success (one-tailed $t$-tests, $p<.01$ ). For females, however, residence of father has no effect upon reproductive success (indeed, females with resident fathers averaged slightly lower reproductive success, but this difference is not significant). Very few young adult females (three out of 28 ) did not have resident mothers, indicating a strong matrilocal residence preference (this small sample size precludes testing the effect of mother's residence on young adult female reproductive success). Many young adult females are highly dependent upon their mothers for child care and other forms of assistance, so this residence pattern is not surprising. Assistance from kin appeared to be one of the criteria upon which residence choice was based (residence of mates

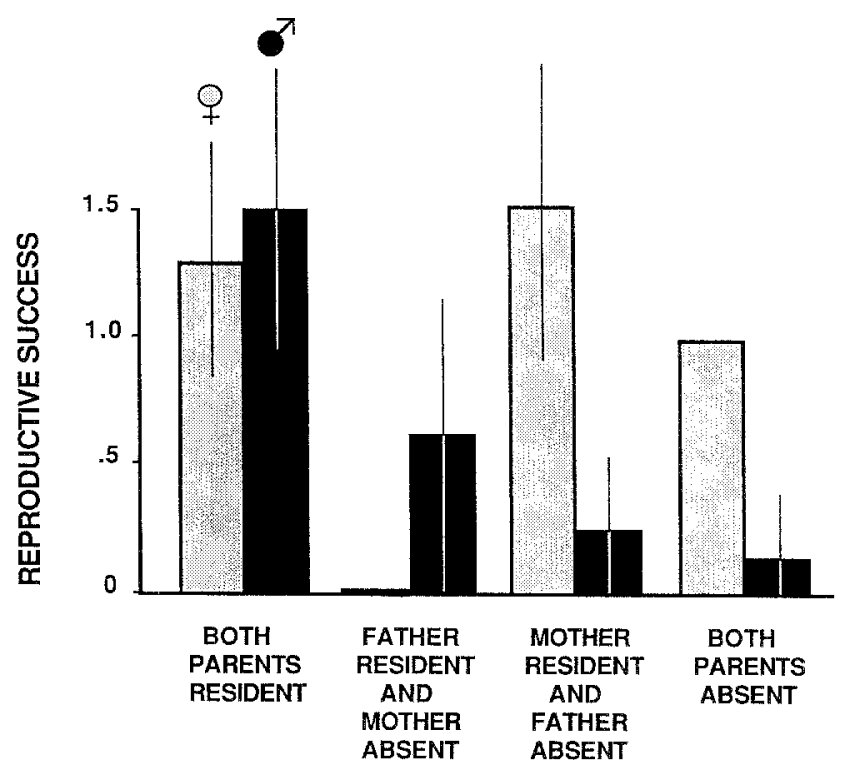

Fig. 5. Parental residence and reproductive success of young adult females and young adult males. There are gender differences in the association between parental residence and the reproductive success of young adults. Residence of father had a strong positive association with the reproductive success of young adult males (black bars), but evidently has no association with the reproductive success of young adult females (gray bars). Sample sizes for the eight categories are: $12,14,1,3,14,9,2$, and 8 . The small sample sizes for females without mothers $(N=1$ for mother absent but father resident, and $N=2$ for both parents absent), indicative of a matrilocal residence preference, precludes statistical tests of the effect of the absence of mother on young adult female reproductive success. Significance levels of $t$-tests for differences between the means are: males with both parents and males with father resident but mother absent vs. males with mother resident but father absent and both parents absent, $p=.001$. For males with mother resident but father absent vs. females with mother resident but father absent, $p=.007$. 
and location of important resources such as land or employment were other criteria). Because males and females have different sources of assistance, it follows that they might make different residence choices (see also Draper and Harpending, 1982; Ember and Ember, 1983; Berté, 1983; Gonzalez, 1969).

Residence of a young man's father in the village probably affects his reproductive success for several reasons. First, a young man is partly dependent upon his father for economic assistance. Fathers help their sons (and daughters) get jobs, often via friendships and connections. Fathers usually control family land; when their sons help cultivate it, they often share in the profits. Many villagers suggested to me that more important than a young man's economic standing is his family's "social" standing in the village. Parents evidently exert influence over their daughter's choice of mates (Flinn, in press a). Indeed, fathers sometimes physically threaten young men that they do not approve of as suitors for their daughters. I once observed a machete waved in the face of a young man by an irate father; the youth ceased courting the man's daughter. A father's "approval" is apparently determined in part by the relationship between the two families (Shakespeare, Romeo and Juliet; Levi-Strauss, 1949). Young men from politically powerful families usually are more successful suitors. Although the residence of father in the village does not increase a young female's reproductive success, he may be important in arranging a mating relationship with a prosperous male for her, thereby increasing the number of her grandchildren (Flinn, in press a). The importance of parental approval may be responsible in part for the association between land and reproductive success noted earlier; if land ownership increases residence stability, then individuals from landed households might be more likely to have parents and other helpful kin resident in the village (see Chagnon, 1979 for a similar association between headmanship and reproductive success among the Yanomamo). Young adults with resident parents do tend to come from households that have more land (average acres $=5.2$ vs. 4.3 ), but the difference is not significant (one-tailed $t$-test, $p=.36$ ).

\section{DISCUSSION}

The data indicate that resource accrual in the study population is associated with biological fitness. The associations between resources and reproduction seem to result primarily from mate choice (including manipulations by parents) by females of prosperous males. These findings are surprisingly congruent with current evolutionary models of mating systems developed from the study of nonhuman organisms (Borgia, 1979; Emlen and Oring, 1977; Thornhill and Alcock, 1983; Vehrencamp and Bradbury, 1984; Flinn and Low, 1986). Testing hypotheses based on evolutionary theory with 
data from human populations, however, poses special problems. Anthropologists have wrestled with the significance of the fact that humans acquired "cultural capacities" (at a minimum, large brains) via organic evolution. Clearly, the cultural transmission of learned behaviors is central to a theory of human adaptation (recent discussions include Alexander 1974, 1979; Boyd and Richerson, 1985; Cavalli-Sforza and Feldman, 1981; Cloak, 1975; Durham, 1976, 1982, in press; Flinn and Alexander, 1982; Konner, 1982; Lumsden and Wilson, 1981; Richerson and Boyd, 1978; Ruyle, 1973; Turke, 1984; Wilson, 1978; Wolpoff, 1980).

Because human capacities for learning culture presumably are products of evolution by natural selection, it seems relevant to examine the extent to which learned human behaviors, such as economic strategies (or other "praxis" strategies) affect the fitness of individual culture bearers. Evolutionary theory predicts that the "utility" that individuals have evolved to "maximize" is genetic representation in future generations. Note that this does not imply that different behaviors are currently due to genetic differences, but rather that they are adaptive responses to different environmental conditions. Here we have a clearly defined "etic" utility (Hirschleifer, 1977) that may in practice involve many "emic" goals (Irons, 1979). In Grande Anse, the strategies that individuals adopt in response to their different micro-environments seem to fit well with the hypothesis that individuals are behaving in ways that maximize their inclusive fitness. Many alternative explanations remain to be tested, however.

There is an important caveat that must be considered when applying such an evolutionary approach to human social behavior. Human social environments are extremely dynamic and full of novelty, and they probably have been so throughout much of our evolutionary history. Hence, any genetic "instructions" are likely to be highly flexible. Environments may change in unpredictable ways, sometimes causing adaptations to previous environments to become "off-track." Some behaviors, such as overeating foods high in sugars, or spending several years in graduate school, may be analogous to "moths flying into candle flames" (Alexander, 1979). It is critical, therefore, to identify the proximate mechanisms of inclusive fitness maximization, that is, the environmental cues that humans might have evolved to base behavioral strategies upon (see Daly and Wilson, 1983; Symons, 1979). It is equally critical to consider the interactions between proximate mechanisms and the different historical and ecological contexts that each individual encounters (see Barth, 1967; Bordieu, 1977).

Among humans, evolved proximate mechanisms might include "satisfaction" or material well-being. For example, just as we have evolved sensory mechanisms that tell us that "sugar is sweet" (presumably because ripe fruits were more nutritious for our ancestors; Barash, 1977), and "sex feels good," 
so the accumulation of resources useful for reproduction might have been selected to be rewarded with positive sensory feedback. The proximate mechanisms that humans evolved in the context of earlier environments, however, might no longer lead to fitness maximization in current environmental conditions. But this is at least a testable proposition. Knowledge of evolved proximate mechanisms would be useful for understanding human behavior, even if some behaviors are no longer associated with fitness maximization in some environments.

In Grande Anse, the link between the proximate satisfaction of socioeconomic success and the evolutionary effect of increased fitness evidently occurs because land ownership leads to greater mating success for males, and possibly greater grandoffspring production for females. This association does not seem to be due to an unequal distribution of "scarce resources" necessary for survival (everyone usually had sufficient food to eat, for example), but rather to an unequal distribution of "social resources" that affect mating opportunities. This tentative conclusion suggests that the application of models from evolutionary ecology to human social behavior will require clever empirical tests and that the models may require considerable modification (see Winterhalder and Smith, 1981; Alexander et al., 1979). In particular, the polygyny threshold model (Verner and Willson, 1966; Orians, 1969) may not be appropriate for human mating systems because there probably is not free choice of mates by females in most human populations (see Chagnon, 1982; Flinn and Low, 1986; Flinn, in press b).

\section{SUMMARY AND CONCLUDING REMARKS}

The major findings of this analysis of demographic and economic data from the village of Grande Anse are: (1) reproductive success is associated with land ownership, largely because of increased mating success by prosperous males, and (2) the reproductive success of young adults is associated with the residence of their parents in the village, evidently because parental assistance is important for acquiring resources and mates. These findings are consistent with an evolutionary perspective of human behavior (Chagnon, 1979 ; Irons, 1979). It is important to note, however, that the "cultural values" held by most individuals in the village seemed to be generally congruent with inclusive fitness maximization, i.e., the proximate mechanisms for fitness maximization seemed to be "on track."

The particular associations between resources and reproduction found in this study are unlikely to occur in all other populations (Hill, 1984; EssockVitale, 1984; Irons, 1979; Vining, in press). The results do suggest, however, the importance of gathering information about individual mating success and assistance from kin, which many previous studies have failed to consider. 


\section{ACKNOWLEDGMENTS}

I would like to thank Susan, Arinthia, Junior, and Andre for friendship and help with the fieldwork. Richard D. Alexander, Robbins Burling, Richard Wrangham, and two anonymous reviewers provided helpful criticism and encouragement. The paper was presented at the AAPA Meeting in Philadelphia on April 12, 1984.

\section{REFERENCES}

Alexander, R. D. (1974). The evolution of social behavior. Annual Review of Ecology and Systematics 5: 325-383.

Alexander, R. D. (1979). Darwinism and Human Affairs. University of Washington Press, Seattle. Alexander, R. D., Hoogland, J. L., Howard, R. D., Noonan, K. M., and Sherman, P. W. (1979). Sexual dimorphisms and breeding systems in pinnipeds, ungulates, primates, and humans. In Chagnon, N., and Irons, W. (eds.), Evolutionary Biology and Human Social Behavior. Duxbury Press, North Scituate, Massachusetts, pp. 402-435.

Barash, D. P. (1977). Sociobiology and Behavior. Elsevier Press, New York.

Barth, F. (1967). On the study of social change. American Anthropologist 69: 661-669.

Bateman, A. J. (1948). Intra-sexual selection in Drosophila. Heredity 2: 349-368.

Bates, D. G., and Lees, S. H. (1979). The myth of population regulation. In Chagnon, N., and Irons, W. (eds.), Evolutionary Biology and Human Social Behavior. Duxbury Press, North Scituate, Massachusetts. pp. 273-289.

Becker, G. S. (1981). A Treatise on the Family. Harvard University Press, Cambridge, Massachusetts.

Berte, N. A. (1983). Reciprocity and exchange among the K'ekchi' Indians. Ph.D. thesis, Department of Anthropology, Northwestern University, University Microfilms, Ann Arbor, Michigan.

Besson, J. (1979). Symbolic aspects of land in the Caribbean: The tenure and transmission of land rights among Caribbean peasantries. In Cross, M., and Marks, A. (eds.), Peasants, Plantations and Rural Communities in the Caribbean. Department of Sociology, University of Surrey, and Department of Caribbean Studies, Royal Institute of Linguistics and Anthropology.

Betzig, L. L. (1983). Despotism and differential reproduction. Ph.D. thesis, Department of Anthropology, Northwestern University, University Microfilms, Ann Arbor, Michigan.

Bordieu, P. (1977). Outline of a Theory of Practice. Cambridge University Press, Cambridge.

Borgia, G. (1979). Sexual selection and the evolution of mating system. In Blum, M. F., and Blum, N. (eds.), Sexual Selection and Reproductive Competition in Insects. Academic Press, New York.

Boyd, R., and Richerson, P. J. (1985). Culture and the Evolutionary Process. University of Chicago Press, Chicago.

Cavalli-Sforza, L., and Feldman, M. (1981). Cultural Transmission and Evolution. Princeton University Press, Princeton, New Jersey.

Chagnon, N. A. (1974). Studying the Yanomamo. Holt, Rinehart and Winston, New York.

Chagnon, N. A. (1979). Is reproductive success equal in egalitarian societies? In Chagnon, N., and Irons, W. (eds.), Evolutionary Biology and Human Social Behavior. Duxbury Press, North Scituate, Massachusetts, pp. 374-401.

Chagnon, N. A. (1982). Sociodemographic attributes of nepotism in tribal populations: Man the rule breaker. In King's College Sociobiology Groups (eds.), Current Problems in Sociobiology. University of Cambridge Press, Cambridge.

Chagnon, N. A., Flinn, M. V., and Melancon, T. (1979). Sex ratio variations among the Yanomamo indians. In Chagnon, N., and Irons, W. (eds.), Evolutionary Biology and Human Social Behavior. Duxbury Press, North Scituate, Massachusetts, pp. 290-320. 
Chance, M. R. A. (1962). Social behavior and primate evolution. In Washburn, S. L. (ed.), Social Life of Early Man. Methuen, London.

Clarke, E. (1957). My Mother Who Fathered Me. Allen and Unwin, London.

Cloak, F. T., Jr. (1975). Is a cultural ethology possible? Human Ecology 3: 161-182.

Daly, M., and Wilson, M. (1982). Whom are newborn babies said to resemble? Ethology and Sociobiology 3: 69-78.

Daly, M., and Wilson, M. (1983). Sex, Evolution, and Behavior. Duxbury Press, Boston.

Draper, P., and Harpending, H. (1982). Father absence and reproductive strategy: An evolutionary perspective. Journal of Anthropological Research 38: 255-273.

Driver, E. D. (1963). Differential Fertility in Central India. Princeton University Press, Princeton, New Jersey.

Durham, W. (1976). The adaptive significance of cultural behavior, Human Ecology 4: 89-121.

Durham, W. (1982). The interactions of genetic and cultural evolution: Models and examples. Human Ecology 10: 299-334.

Durham, W. (in press). Coevolution: Genes, Culture, and Human Diversity. University Press, Stanford, Stanford, California.

Ember, M., and Ember, C. R. (1983). Marriage, Family and Kinship. HRAF Press, New Haven.

Emlen, S. T., and Oring, L. W. (1977). Ecology, sexual selection, and the evolution of mating systems. Science 197: 215-223.

Essock-Vitale, S. (1984). The reproductive success of wealthy Americans. Ethology and Sociobiology 5: 45-49.

Fisher, R. A. (1958). The Genetical Theory of Natural Selection (2nd Ed.). Dover Press, New York (originally published in 1930).

Flinn, M. V., (1983). Resources, mating, and kinship: The behavioral ecology of a Trinidadian village. Ph.D. thesis, Department of Anthropology, Northwestern University, University Microfilms, Ann Arbor, Michigan.

Flinn, M. V. (in press a). Parent-offspring interactions in a Trinidadian village: Daughter guarding. In Betzig, L., Muder, M., and Turke P. (eds.), Human Reproductive Behavior. Cambridge University Press, Cambridge.

Flinn, M. V. (in press b). Mate guarding in a Trinidadian village. Ethology and Sociobiology.

Flinn, M. V., and Alexander, R. D. (1982). Cultural theory: The developing synthesis from biology. Human Ecology 10: 383-400.

Flinn, M. V., and Low, B. S. (1986). Resource distribution, social competition and mating patterns in human societies. In Rubenstein, D. I. and Wrangham, R. W. (eds.), Ecology and Social Evolution. Princeton University Press, Princeton, New Jersey.

Fox, R. (1972). Alliance and constraint: Sexual selection in the evolution of human kinship systems. In Campbell, B. (ed.), Sexual Selection and the Descent of Man 1871-1971. Aldine, Chicago.

Gonzalez, N. S. (1969). Black Carib Houshold Structure. University of Washington Press, Seattle.

Goody, J. (1976). Production and Reproduction. Cambridge University Press, Cambridge.

Hamilton, W. D. (1964). The genetical evolution of social behavior I. and II. Journal of Theoretical Biology 7: 1-52.

Hill, J. (1984). Prestige and reproductive success in man. Ethology and Sociobiology 5: 77-95.

Hirschleifer, J. (1977). Economics from a biological viewpoint. Journal of Law and Economics 20: $1-52$.

Hirschleifer, J. (1978). Natural economy versus political economy. Journal of Social and Biological Structures 1: 319-337.

Irons, W. (1979). Cultural and biological success. In Chagnon, N., and Irons, W. (eds.), Evolutionary biology and human social behavior. Duxbury Press, North Scituate, Massachusetts, pp. 257-272.

Irons, W. (1983). Human female reproductive strategies. In Wasser, S., and Waterhouse, M. (eds.), Social Behavior of Female Vertebrates. Academic Press, New York.

Kaplan, H., and K. Hill, (1985). Hunting ability and reproductive success among male Ache foragers: Preliminary results. Current Anthropology 26: 131-133.

Konner, M. (1982). The Tangled Wing: Biological Constraints on the Human Spirit. Aldine Press, Hawthorne, New York.

Levi-Strauss, C. (1949). Les Structures Elementaries de la Parente. Plon, Paris. 
Lumsden, C. J., and Wilson, E. O. (1981). Genes, Mind and Culture. Harvard University Press, Cambridge, Massachusetts.

Meillasoux, C. (1972). From reproduction to production. Economy and Society 1: 93-105.

Neel, J. (1980). On being headman. Perspectives in Biology and Medicine 23: 277-294.

Orians, G. (1969). On the evolution of mating systems in birds and mammals. American Naturalist 21: 589-603.

Pelto, P. J., and Pelto, G. H. (1975). Intra-cultural diversity: Some theoretical issues. American Ethnologist 2: 1-18.

Richerson, P. J., and Boyd, R. (1978). A dual inheritance model of the human evolutionary process, I. Basic concepts and a simple model. Journal of Social and Biological Structures 1: 127-154.

Rodman, H. (1971). Lower Class Families. Oxford University Press, London.

Ruyle, E. E. (1973). Genetic and cultural pools: Some suggestions for a unified theory of biocultural evolution. Human Ecology 1: 201-215.

Smith, M. G. (1962). West Indian Family Structure. University of Washington Press, Seattle.

Symons, D. (1979). The Evolution of Human Sexuality. Oxford University Press, Oxford.

Thornhill, R., and Alcock J. (1983). The Evolution of Insect Mating Systems. Harvard University Press, Cambridge, Massachusetts.

Trivers, R. L. (1972). Parental investment and sexual selection. In Campbell, B. (ed.), Sexual Selection and the Descent of Man 1871-1971. Aldine, Chicago.

Turke, P. (1984). Ph.D. thesis, Department of Anthropology, Northwestern University, University Microfilms, Ann Arbor, Michigan.

Turke, P., and Betzig, L. L. (in press). Those that have do: Status and reproductive success on Ifaluk. Ethology and Sociobiology.

Vayda, A. P. and McCay, B. J. (1975). New directions in ecology and ecological anthropology. Annual Review of Anthropology 4: 293-306.

Vehrencamp, S., and Bradbury, J. (1984). Mating systems and ecology. In Krebs, J. R., and Davies, N. B. (eds.), Behavioral Ecology, (2nd Ed.), Sinauer Associated, Sunderland, Massachusetts.

Verner, J., and Willson, M. F. (1966). The influence of habitats on mating systems of North American passerine birds. Ecology 47: 143-147.

Vining, D. R., Jr. (in press). Social versus reproductive success: The central theoretical problem of human sociobiology. The Behavioral and Brain Sciences.

West-Eberhard, M. J. (1975). The evolution of social behavior by kin selection. Quarterly Review of Biology 50: 1-33.

Williams, G. C. (1966). Adaptation and Natural Selection. Princeton University Press, Princeton New Jersey.

Wilson, E. O. (1975). Sociobiology. Harvard University Press, Cambridge, Massachusetts.

Wilson, E. O. (1978). On Human Nature. Harvard University Press, Cambridge, Massachusetts.

Winterhalder, B., and Smith, E. A. (eds.) (1981). Hunter-Gatherer Foraging Strategies. University of Chicago Press, Chicago.

Wolpoff, M. H. (1980). Paleoanthropology. Knopf, New York. 